\title{
UMIDIFICAÇÃO DE SEMENTES DE GIRASSOL APÓS ULTRASSECAGEM EM SÍLICA GEL E CÂMARA DE SECAGEM ${ }^{1}$
}

\author{
SOLANGE CARVALHO BARRIOS ROVERI JOSÉ², ANTONIETA NASSIF SALOMÃO, \\ ROSÂNGELA CALDAS MUNDIMㄴ, JULIANO GOMES PÁDUA 5 .
}

\begin{abstract}
RESUMO - Dentre os processos que precedem a conservação em longo prazo, a secagem tem papel fundamental, uma vez que o conteúdo de água das sementes afeta diretamente a sua longevidade. Os objetivos desse trabalho foram pesquisar o efeito da umidificação prévia das sementes após ultrassecagem em diferentes teores de água sobre a qualidade fisiológica de sementes de girassol. Sementes com conteúdo inicial de água de 4,7\% foram embebidas previamente até conteúdo de água de $10,2 \%$, e submetidas à secagem lenta, conduzida em câmara de secagem, e à secagem rápida, em sílica gel, até conteúdos de água de 7,$4 ; 3,2 ; 2,9 \%$ e 5,3; 3,2; 2,1\%, respectivamente. Após a secagem rápida ou lenta, as sementes foram submetidas ou não à umidificação em caixas tipo "gerbox" até o teor de água de 15,8 a 17\% e então avaliadas quanto à germinação, peso da matéria seca de raiz, parte aérea e total das plântulas e teste de condutividade elétrica. O delineamento experimental foi o inteiramente casualizado em esquema fatorial 5 (teores de água) x 2 (com e sem umidificação). Quando utilizado a secagem rápida, a germinação das sementes não é prejudicada, e a secagem lenta, até conteúdo de água de $2,9 \%$, proporciona uma redução na germinação das sementes. Sementes de girassol podem ser desidratadas tanto em sílica gel quanto em câmara de secagem até teores de água de $3,2 \%$, sem perda de germinação e vigor. O tratamento de umidificação após secagem propicia um melhor desenvolvimento de raiz e menores valores de condutividade elétrica nas sementes desidratadas em sílica gel e em câmara de secagem.
\end{abstract}

Termos para indexação: dessecação, Helianthus annuus, germinação, vigor

\section{HUMIDIFICATION IN SILICA GEL AND CHAMBER OF SUNFLOWER SEEDS AFTER ULTRADRYING}

\begin{abstract}
Among the long term conservation activities, drying is fundamental since the seed water content directly affects the seed longevity. The aims of this study were to evaluate the effect of pre-humidification after ultradrying on the physiological quality of sunflower seeds. Seeds with $4.7 \%$ water content were re-hydrated to $10.2 \%$ water content and slow drying was conducted in a dry chamber and fast drying in silica gel to $7.7,3.2,2.9 \%$ and $5.3 \%, 3.2$ and $2.1 \%$, respectively. After drying, seeds were submitted to humidification, or not, in a "gerbox" type box to 15.8 to $17 \%$ water content and evaluated for the characteristics germination, weight of root dry matter, shoot and total seedlings and the electric conductivity test. A randomized complete design was used in a 5 (water content) x 2 (with and without humidification) factorial arrangement. Germination was not affected by fast drying, while seeds submitted to slow drying to $2.9 \%$ water content presented
\end{abstract}

Submetido em 02/02/2009. Aceito para publicação em 13/08/2009.

${ }^{2}$ Eng. Agr., DSc., Embrapa Recursos Genéticos e Biotecnologia, Caixa Postal 2.372, CEP: 70770-917 - Brasília, DF solangebr@cenargen. embrapa.br

${ }^{3}$ Eng. Florestal., MSc., Embrapa Recursos Genéticos e Biotecnologia, antoniet@cenargen.embrapa.br
${ }^{4}$ Geógrafa., Embrapa Recursos Genéticos e Biotecnologia, rosa@cenargen. embrapa.br

${ }^{5}$ Eng. Agr., DSc., Embrapa Recursos Genéticos e Biotecnologia, jgpadua@ cenargen.embrapa.br 
reduced germination. Sunflower seeds can be dried to $3.2 \%$ of water content, without decrease in germination or vigour. The humidification treatment after drying results in better root development and lower electric conductivity values in dried seeds.

Index terms: desiccation, Helianthus annuus, germination, vigor

\section{INTRODUÇÃO}

A cultura de girassol (Helianthus annuus L.) vem se destacando por seu potencial de uso, atendendo tanto as demandas nutricionais como as industriais, com adequadas características agronômicas, qualidade de óleo na alimentação (Oliveira e Vieira, 2004), além da utilização como fonte de energia alternativa e como ornamental.

Para que os recursos genéticos desta espécie estejam disponíveis, é importante que as sementes armazenadas em longo prazo em banco de germoplasma $\left(-20^{\circ} \mathrm{C}\right)$, mantenham sua integridade genética, fisiológica, sanitária e física.

Dentre as atividades que precedem a conservação a longo prazo, a secagem tem papel fundamental, uma vez que a longevidade das sementes está diretamente relacionada a seu teor de água, que pode favorecer o processo de deterioração durante o armazenamento. No entanto, a secagem, dependendo da forma como é conduzida, pode danificar as sementes, implicando na redução de sua qualidade fisiológica. Um dos fatores que influencia na tolerância dos tecidos vegetativos à dessecação é a taxa de secagem (Bewley e Black, 1994), que depende da capacidade do genótipo de resistir à rápida remoção de água (José et al., 2005).

$\mathrm{O}$ teor de água das sementes recomendado para a conservação a longo prazo varia de 3 a $7 \%$. Para atingir tais valores, as sementes são submetidas à secagem em câmara com temperatura e umidade relativa do ar de $22 \pm 3^{\circ} \mathrm{C}$ e $15 \pm 3 \%$, respectivamente. Outro método de secagem em banco de germoplasma de semente é a utilização de sílica gel, que permite atingir teores de água nas sementes de 1,5 a 3,0\% (ultrassecagem) (Pérez-Garcia et al., 2007). Este método, permite uma secagem rápida e proporciona um ambiente asséptico, além de que, a alteração na umidade da sílica é observada por meio da variação da sua cor. O efeito benéfico da ultrassecagem foi verificado em sementes de aveia e cevada e de algumas espécies de planta daninha, após 110 anos de armazenamento a 10 e $15^{\circ} \mathrm{C}$ (Steiner e Ruckenbauer,1995).
Apesar da redução da umidade ser importante para a conservação de sementes, existe um conteúdo crítico de água, abaixo do qual, a longevidade não pode ser prolongada (Ellis e Hong, 2006). O efeito da secagem a baixos conteúdos de água e armazenamento em diferentes temperaturas foi estudado em sementes de cenoura, amendoim, alface, colza e cebola. Sementes secas até teor de água de 5,5 a 6,8\%, e 2,0 a $3,7 \%$ (ultrassecagem) foram armazenadas hermeticamente em pacotes de alumínio em temperaturas de 20 ou $-20^{\circ} \mathrm{C}$. Foi possível confirmar que temperatura de $-20^{\circ} \mathrm{C}$ permitiu a sobrevivência das sementes por um período de dez anos de armazenamento numa faixa ampla de umidade (Hong et al., 2005).

Para sementes de trevo vermelho e alfafa armazenadas com diferentes umidades, o conteúdo crítico de umidade, variou entre 4 e $6 \%$, dependendo da temperatura de armazenamento. Acima dessa umidade crítica ocorre redução na longevidade e abaixo, não ocorre efeito adicional. Essa umidade crítica em sementes armazenadas à $-20^{\circ} \mathrm{C}$ foi mais elevada, comparada com temperaturas mais elevadas (Ellis e Hong, 2006).

Para avaliação da perda de qualidade das sementes, após a desidratação, é importante conduzir testes de vigor e de integridade das membranas associados ao teste de germinação. Isto porque, os sintomas fisiológicos mais evidentes da deterioração das sementes são observados durante a germinação e o desenvolvimento inicial das plântulas (Coolbear, 1995). Outra manifestação de deterioração é a desestruturação do sistema de membranas, como conseqüência do ataque aos seus constituintes químicos pelos radicais livres. A instabilidade química dos lipídios constitui um dos fatores preponderantes para a queda do desempenho das sementes de várias espécies, especialmente das oleaginosas (Carvalho, 1994).

Outra preocupação que se deve ter no manejo de bancos de germoplasma de sementes é o dano por embebição durante a germinação das sementes. Como o conteúdo de água é muito baixo, as sementes podem apresentar baixa porcentagem de 
germinação e baixo vigor, devido aos danos ocasionados pela rápida absorção de água durante a condução dos testes. Esses danos podem ser minimizados pelo condicionamento (umidificação) das sementes, antes da realização do teste de germinação (Hong e Ellis, 1996). Seria importante estudar a influência desse tratamento na avaliação da qualidade das sementes, de forma a representar seu potencial germinativo.

O objetivo dessa pesquisa foi avaliar o efeito da umidificação prévia das sementes após ultrassecagem em diferentes teores de água em câmara de secagem e em sílica gel na qualidade fisiológica de sementes de girassol.

\section{MATERIAL E MÉTODOS}

O experimento foi conduzido nos Laboratórios de Sementes e de Criobiologia Vegetal, da Embrapa Recursos Genéticos e Biotecnologia - Brasília/DF, no ano de 2008.

Foram utilizadas sementes de girassol (Helianthus annuus L.), com conteúdo de água de $4,7 \%$, provenientes da Empresa de Sementes "Helianthus do Brasil", situada em Uberlândia - MG. Em função do baixo teor de água, as sementes foram inicialmente pré-embebidas em germinador a $25^{\circ} \mathrm{C}$, por 22 horas, e mantidas em latas hermeticamente fechadas para estabilização da umidade das sementes. $\mathrm{O}$ teor de água das sementes atingiu 10,2\%, constituindo esta, a umidade inicial (Ui). Sementes não embebidas, com umidade original (Uo) de 4,7\%, serviram como controle.

Para a desidratação das sementes, dois métodos foram avaliados separadamente: câmara de secagem (secagem lenta) e sílica gel (secagem rápida). As sementes, acondicionadas em saco de papel Kraft, foram colocadas em câmara com variação da umidade relativa do ar de 17,4 a $20,4 \%$ e da temperatura de 20 a $22^{\circ} \mathrm{C}$. Os sacos de papel contendo as sementes foram periodicamente misturados. Para a secagem em sílica gel, foram utilizadas caixas acrílicas, tipo "gerbox", com dimensões de $11 \mathrm{~cm}$ x $11 \mathrm{~cm}$ x 3,5cm, contendo $90 \mathrm{~g}$ de sílica gel, indicador azul. Sobre a sílica em uma tela de inox, as sementes foram distribuídas uniformemente em camada única. As caixas foram tampadas e vedadas com filme PVC, permanecendo em ambiente de laboratório com variação de umidade relativa do ar de 35,4 a $45,4 \%$ e de temperatura de 20,8 a $25,8^{\circ} \mathrm{C}$. Ao sexto dia de secagem, a sílica gel foi substituída.

Para controle da perda de umidade, as sementes, com massa original determinada, foram pesadas periodicamente em uma balança com precisão de 0,001 g. O teor de água para cada período e método de secagem foi ajustado de acordo com a equação, citada por Valle (2003):
$\mathrm{P}_{2}=[(100-\mathrm{A}) / 100-\mathrm{B}] \times \mathrm{P}_{1}$,em que:

$\mathrm{P}_{2}=$ peso final das sementes;

$\mathrm{P}_{1}=$ peso inicial das sementes;

$\mathrm{A}=$ teor de água inicial;

$\mathrm{B}=$ teor de água desejado

A partir da avaliação das massas obtidas em cada período de secagem, foram selecionados os teores de água de 5,3, 3,2 e 2,1\% para a secagem rápida, e 7,4, 3,2 e 2,9\% para a secagem lenta e o teor de água final das sementes foi determinado em estufa de secagem.

Para a avaliação da qualidade fisiológica, as sementes foram submetidas aos seguintes tratamentos: a) umidificação: as sementes foram esparramadas em camada única sobre uma tela de inox colocada dentro de caixa tipo "gerbox", contendo $40 \mathrm{~mL}$ de água, de modo que não entrassem em contato com a água. As caixas foram mantidas por 24 horas em condições de laboratório. Após esse período foram realizadas as avaliações fisiológicas e a determinação da umidade das sementes e; b) sem umidificação, em que os testes fisiológicos e de umidade das sementes foram realizados logo após secagem.

O grau de umidade das sementes após embebição, secagem e umidificação foi determinado com duas subamostras de $2 \mathrm{~g}$ de sementes para cada tratamento, em estufa regulada a $105 \pm 3^{\circ} \mathrm{C}$, durante 24 horas (Brasil, 1992). $\mathrm{O}$ teor de água foi calculado com base na massa fresca, por meio da média obtida de cada uma das subamostras.

Para o teste de germinação, quatro repetições de 25 sementes foram semeadas entrepapel toalhatipo "Germitest ${ }^{\mathbb{B}}$ ", umedecido com água destilada na proporção de $2,5 \mathrm{~mL} \cdot \mathrm{g}^{-1} \mathrm{de}$ papel. As sementes permaneceram em germinador regulado à $25^{\circ} \mathrm{C}$ e as avaliações de plântulas normais foram feitas no terceiro (primeira contagem) e no quinto (última contagem) dias após a instalação do teste (Brasil, 1992). Na primeira contagem foram avaliadas plântulas que apresentaram raiz primária normal, independente da proporção dos cotilédones expostos. Para a avaliação do comprimento de raiz foi computado o número de plântulas normais com raiz primária $\geq 7 \mathrm{~cm}$ de comprimento nas duas contagens do teste de germinação.

A massa de matéria seca de raiz, parte aérea e total foi determinada utilizando-se as plântulas normais provenientes da contagem final do teste de germinação. A parte aérea e a radicular foram separadas sem qualquer parte da semente e tecido cotiledonar, e acondicionadas separadamente, por repetição em sacos de papel. Essas estruturas foram dessecadas em estufa com circulação forçada de ar, regulada à temperatura de $65^{\circ} \mathrm{C}$, por 72 horas. Após esse período, as 
amostras foram retiradas da estufa, colocadas para esfriar em dessecador contendo sílica, e posteriormente, pesadas em balança com precisão de $0,001 \mathrm{~g}$. A massa obtida foi dividida pelo número de parte aérea ou raiz presente em cada repetição, resultando massa média de matéria seca em gramas por plântula (Krzyzanowski et al., 1999). A massa de matéria seca total foi obtida pelo somatório da massa da matéria seca da parte aérea e raiz.

Para a determinação da condutividade elétrica, foram utilizadas quatro repetições de 25 sementes aparentemente intactas e previamente pesadas para cada tratamento. As sementes foram imersas em $75 \mathrm{~mL}$ de água destilada por 24 horas e mantidas à temperatura de $25^{\circ} \mathrm{C}$. Por meio de um condutivímetro de massa da marca Digimed DM $31^{\circledR}$, previamente calibrado, foi efetuada a leitura da condutividade da solução de embebição das sementes e os resultados expressos em $\mu \mathrm{S} \mathrm{cm}^{-1} \mathrm{~g}^{-1}$ de sementes (Vieira e Krzyzanowski, 1999).

$\mathrm{O}$ delineamento experimental foi o inteiramente casualizado, com quatro repetições, em esquema fatorial ( 5 $\mathrm{x} 2$ ), com cinco umidades das sementes e dois tratamentos de umidificação (com e sem), para a secagem lenta e rápida, separadamente. Após análise de variância foram realizados os desdobramentos dos graus de liberdade dos tratamentos, isolando os efeitos principais dos fatores e os efeitos das interações entre os fatores (Banzatto e Kronka, 1995). Os dados foram submetidos a análise de variância e as médias, comparadas pelo teste de Scott - Knott em nível de 5\%. As análises foram realizadas no programa estatístico Sisvar ${ }^{\circledR}$ (Sistema de Análise de Variância) (Ferreira, 2000).

\section{RESULTADOS E DISCUSSÃO}

Na Tabela 1, encontram-se os valores do teor de água das sementes após os diferentes tratamentos de secagem e posterior umidificação. O período necessário para que as sementes desidratadas em sílica atingissem teor de água inferior a $3 \%$ foi de quase oito dias, e na secagem em câmara o processo foi mais lento, sendo necessários quase 27 dias. A pré-embebição por 22 horas foi eficiente para as sementes submetidas aos dois métodos de secagem, proporcionando valores de teor de água próximos a 16$18 \%$, conforme mencionado por Hong e Ellis (1996). A absorção de água pelas sementes estabilizou-se nessa faixa de umidade, independente do teor de água atingida após secagem.

TABELA 1. Teores médios de água (\%) de sementes de girassol submetidas à desidratação em sílica gel e câmara de secagem e ao tratamento de umidificação.

\begin{tabular}{|c|c|c|c|}
\hline \multirow{2}{*}{ Tratamento } & \multicolumn{2}{|c|}{ Tratamento de secagem } & \multirow{2}{*}{$\frac{\text { Umidificação }}{\% \text { de umidade }}$} \\
\hline & Período de secagem & $\%$ de umidade & \\
\hline Uo & - & 4,7 & 16,1 \\
\hline $\mathrm{Ui}$ & - & 10,2 & 16,5 \\
\hline U1S & $2 \mathrm{~h} 30 \mathrm{~min}(0,10 \mathrm{dias})$ & 5,3 & 17,0 \\
\hline $\mathrm{U} 2 \mathrm{~S}$ & $22 \mathrm{~h} 00 \mathrm{~min}(0,92 \mathrm{dias})$ & 3,2 & 16,2 \\
\hline U3S & $190 \mathrm{~h} 45 \mathrm{~min}(7,95$ dias $)$ & 2,1 & 15,8 \\
\hline $\mathrm{U} 1 \mathrm{C}$ & $3 \mathrm{~h} 35 \min (0,15$ dias $)$ & 7,4 & 16,1 \\
\hline $\mathrm{U} 2 \mathrm{C}$ & $72 \mathrm{~h} 55 \mathrm{~min}(3,04$ dias $)$ & 3,2 & 16,2 \\
\hline $\mathrm{U} 3 \mathrm{C}$ & $644 \mathrm{~h} 25 \mathrm{~min}(26,85$ dias $)$ & 2,9 & 16,8 \\
\hline
\end{tabular}

Uo: umidade original; Ui: umidade após pré-embebição para obter umidade inicial; U1S, U2S, U3S: umidades obtidas após três períodos de secagem em sílica; U1C, U2C, U3C: umidades obtidas após três períodos de secagem em câmara.

Os resultados da avaliação da qualidade fisiológica das sementes desidratadas em sílica gel e que apresentaram diferenças significativas entre os teores de água e tratamento de umidificação encontram-se nas Tabelas 2 a 6 . Apenas as variáveis com efeito significativo para os tratamentos estudados que foram apresentados em Tabelas. Independente do teor de água das sementes e do tratamento de umidificação, não houve diferença significativa entre os valores médios de plântulas normais obtidas na primeira e última contagem do teste de germinação, $89 \%$ e $92 \%$, respectivamente (dados não apresentados). Diferenças significativas entre os teores de água após secagem e tratamento de umidificação foram observadas para os testes que avaliaram o vigor das sementes, como o comprimento de plântulas na primeira contagem do teste de germinação (Tabela 2), teste de condutividade elétrica (Tabela 3), e massa da matéria seca 
(Tabelas 4, 5 e 6). Sementes desidratadas até conteúdos de água de $5,3 \%$ (U1S) e 3,2\% (U2S) apresentaram maiores porcentagens de plântulas normais na primeira contagem com raiz $>7 \mathrm{~cm}$, maiores valores de massa de matéria seca de raiz, parte aérea e total (Tabelas 2, 4, 5 e 6). A massa da matéria seca da raiz dessas sementes foi estatisticamente igual a das sementes não secadas (Uo: umidade original, Tabela 4).

TABELA 2. Valores médios de plântulas normais $(\%)$ com raiz $\geq 7 \mathrm{~cm}$, obtidos na primeira contagem do teste de germinação, com e sem umidificação, de sementes de girassol desidratadas em sílica gel com diferentes conteúdos de água.

\begin{tabular}{lcccccc}
\hline Tratamentos & Uo $(4,7 \%)$ & Ui $(10,2 \%)$ & U1S $(5,3 \%)$ & U2S (3,2\%) & U3S (2,1\%) & Média \\
\hline Com umidificação & $53 \mathrm{aA}$ & $45 \mathrm{aA}$ & $44 \mathrm{aA}$ & $59 \mathrm{aA}$ & $49 \mathrm{aA}$ & $50 \mathrm{~A}$ \\
Sem umidificação & $26 \mathrm{bB}$ & $39 \mathrm{aA}$ & $54 \mathrm{aA}$ & $43 \mathrm{aB}$ & $25 \mathrm{bB}$ & $37 \mathrm{~B}$ \\
\hline Média & $40 \mathrm{~b}$ & $42 \mathrm{~b}$ & $49 \mathrm{a}$ & $51 \mathrm{a}$ & $37 \mathrm{~b}$ & \\
\hline
\end{tabular}

Médias seguidas pela mesma letra minúscula na linha, e maiúscula na coluna, não diferem estatisticamente pelo teste Scott Knott a 5\% de probabilidade. Uo: umidade original; Ui: umidade após pré-embebição para obter umidade inicial; U1S, U2S, U3S: umidades obtidas após três períodos de secagem em sílica.

TABELA 3. Valores médios de condutividade elétrica $\left(\mu \mathrm{S} \mathrm{m}^{-1} \mathrm{~g}^{-1}\right)$, obtidos com e sem umidificação de sementes de girassol desidratadas em sílica gel com diferentes teores de água.

\begin{tabular}{lllllll}
\hline Tratamentos & Uo $(4,7 \%)$ & Ui $(10,2 \%)$ & U1S $(5,3 \%)$ & U2S (3,2\%) & U3S (2,1\%) & Média \\
\hline Com umidificação & $72,88 \mathrm{aA}$ & $67,51 \mathrm{aA}$ & $67,19 \mathrm{aA}$ & $71,06 \mathrm{aA}$ & $71,12 \mathrm{aA}$ & $69,95 \mathrm{~A}$ \\
Sem umidificação & $81,79 \mathrm{bB}$ & $70,20 \mathrm{aA}$ & $84,59 \mathrm{bB}$ & $78,64 \mathrm{bA}$ & $75,42 \mathrm{aA}$ & $78,13 \mathrm{~B}$ \\
\hline Média & $77,33 \mathrm{a}$ & $68,85 \mathrm{a}$ & $75,89 \mathrm{a}$ & $73,27 \mathrm{a}$ & $73,27 \mathrm{a}$ & \\
\hline
\end{tabular}

Médias seguidas pela mesma letra minúscula na linha, e maiúscula na coluna, não diferem estatisticamente pelo teste Scott Knott a 5\% de probabilidade. Uo: umidade original; Ui: umidade após pré-embebição para obter umidade inicial; U1S, U2S, U3S: umidades obtidas após três períodos de secagem em sílica.

TABELA 4. Valores médios da massa da matéria seca da raiz (g), obtidos, com e sem umidificação, de sementes de girassol desidratadas em sílica com diferentes teores de água.

\begin{tabular}{lcccccc}
\hline Tratamentos & Uo $(4,7 \%)$ & Ui $(10,2 \%)$ & U1S $(5,3 \%)$ & U2S $(3,2 \%)$ & U3S $(2,1 \%)$ & Média \\
\hline Com umidificação & $0,0036 \mathrm{aB}$ & $0,0037 \mathrm{aA}$ & $0,0046 \mathrm{aA}$ & $0,0046 \mathrm{aB}$ & $0,0023 \mathrm{bB}$ & $0,0038 \mathrm{~B}$ \\
Sem umidificação & $0,0066 \mathrm{aA}$ & $0,0038 \mathrm{bA}$ & $0,0060 \mathrm{aA}$ & $0,0066 \mathrm{aA}$ & $0,0052 \mathrm{aA}$ & $0,0056 \mathrm{~A}$ \\
\hline Média & $0,0051 \mathrm{a}$ & $0,0037 \mathrm{~b}$ & $0,0053 \mathrm{a}$ & $0,0056 \mathrm{a}$ & $0,0038 \mathrm{~b}$ & \\
\hline
\end{tabular}

Médias seguidas pela mesma letra minúscula na linha, e maiúscula na coluna, não diferem estatisticamente pelo teste Scott Knott a 5\% de probabilidade. Uo: umidade original; Ui: umidade após pré-embebição para obter umidade inicial; U1S, U2S, U3S: umidades obtidas após três períodos de secagem em sílica.

TABELA 5. Valores médios da massa da matéria seca da parte aérea (g), obtidos, com e sem umidificação, de sementes de girassol, desidratadas em sílica com diferentes teores de água.

\begin{tabular}{lllllll}
\hline Tratamentos & Uo $(4,7 \%)$ & Ui $(10,2 \%)$ & U1S $(5,3 \%)$ & U2S $(3,2 \%)$ & U3S (2,1\%) & Média \\
\hline Com umidificação & $0,0066 \mathrm{cB}$ & $0,0108 \mathrm{bB}$ & $0,0137 \mathrm{aA}$ & $0,0137 \mathrm{aA}$ & $0,0083 \mathrm{cB}$ & $0,0106 \mathrm{~B}$ \\
Sem umidificação & $0,0140 \mathrm{aA}$ & $0,0127 \mathrm{aA}$ & $0,0139 \mathrm{aA}$ & $0,0144 \mathrm{aA}$ & $0,0133 \mathrm{aA}$ & $0,0137 \mathrm{~A}$ \\
\hline Média & $0,0103 \mathrm{~b}$ & $0,0118 \mathrm{~b}$ & $0,0138 \mathrm{a}$ & $0,0141 \mathrm{a}$ & $0,0108 \mathrm{~b}$ & \\
\hline
\end{tabular}


TABELA 6. Valores médios do peso da matéria seca total (g), obtidos, com e sem umidificação, de sementes de girassol desidratadas em sílica com diferentes teores de água.

\begin{tabular}{lllllll}
\hline Tratamentos & Uo $(4,7 \%)$ & Ui $(10,2 \%)$ & U1S 5,3\%) & U2S 3,2\%) & U3S 2,1\%) & Média \\
\hline Com umidificação & $0,0103 \mathrm{cB}$ & $0,0145 \mathrm{bA}$ & $0,0183 \mathrm{aA}$ & $0,0183 \mathrm{aA}$ & $0,0105 \mathrm{cB}$ & $0,0144 \mathrm{~B}$ \\
Sem umidificação & $0,0206 \mathrm{aA}$ & $0,0166 \mathrm{bA}$ & $0,0199 \mathrm{aA}$ & $0,0211 \mathrm{aA}$ & $0,0185 \mathrm{bA}$ & $0,0193 \mathrm{~A}$ \\
\hline Média & $0,0154 \mathrm{~b}$ & $0,0155 \mathrm{~b}$ & $0,0191 \mathrm{a}$ & $0,0197 \mathrm{a}$ & $0,0145 \mathrm{~b}$ & \\
\hline
\end{tabular}

Médias seguidas pela mesma letra minúscula na linha, e maiúscula na coluna, não diferem estatisticamente pelo teste Scott Knott a 5\% de probabilidade. Uo: umidade original; Ui: umidade após pré-embebição para obter umidade inicial; U1S, U2S, U3S: umidades obtidas após três períodos de secagem em sílica.

No teste de condutividade elétrica (Tabela 3), a média geral do valor de condutividade elétrica para as sementes que não foram submetidas ao umedecimento foi maior, de $78,13 \mu \mathrm{S} \mathrm{cm}^{-1} \mathrm{~g}^{-1}$ de sementes, e não houve diferenças entre os diferentes teores de água. $\mathrm{O}$ valor da condutividade é função da quantidade de lixiviados na solução de embebição das sementes, a qual está diretamente relacionada com a integridade das membranas celulares (Vieira e Krzyzanowski, 1999). Sendo assim, sementes em que o sistema de membranas está mais estruturado, deve apresentar uma menor lixiviação de seus exudatos. No entanto, parece que a taxa de secagem influenciou os resultados de condutividade nas sementes que não foram submetidas à umidificação. Observa-se na Tabela 1 que a taxa de secagem em sílica gel foi elevada nas primeiras horas do processo. No período de secagem de 2 h30min houve redução do teor de água das sementes de 10,2 para $5,3 \%$, o que pode ter afetado a integridade das membranas das mesmas, refletindo no valor mais elevado de condutividade $\left(84,59 \mu \mathrm{S} \mathrm{cm}^{-1} \mathrm{~g}^{-1}\right.$ de sementes). À medida que a taxa de secagem foi reduzindo, necessitando de 22 horas para que as sementes atingissem 3,2\% de teor de água, o valor de condutividade também reduziu de 84,59 para 78,64 $\mu \mathrm{S} \mathrm{cm}^{-1} \mathrm{~g}^{-1}$ de sementes. A umidade de $2,1 \%$ foi atingida pelas sementes após mais de sete dias de secagem, e essa diminuição da taxa de secagem afetou positivamente o valor de condutividade, reduzindo-o para 75,42 $\mu \mathrm{S} \mathrm{cm}^{-1} \mathrm{~g}^{-1}$ de sementes. É importante ressaltar que, apesar dessa redução da condutividade, estes valores ainda foram superiores a todos os tratamentos com umidificação prévia. Embora a secagem conduzida até a umidade de 5,3\% e sem umidificação tenha proporcionado um maior valor de condutividade elétrica, não foi suficiente para afetar o desempenho fisiológico das sementes, avaliado pelos demais testes. Após a umidificação dessas sementes (U1S), o valor de condutividade foi significativamente inferior, como ocorrido com as sementes com umidade original (Uo).
Com exceção do teste de condutividade elétrica, pôde-se verificar que as umidades de 5,3 e 3,2\% foram adequadas, uma vez que as sementes com estes teores de água superaram o desempenho observado para as sementes do lote original (Tabelas 2, 5 e 6). Na avaliação do efeito da secagem em sementes de girassol, os melhores teores de água encontramse no intervalo recomendado para conservação em longo prazo de sementes, entre 3 a 7\%. Como as sementes utilizadas neste experimento apresentavam boa qualidade fisiológica, estas toleraram bem a secagem até níveis muito baixos de água, ou seja, $2,1 \%$, sugerindo que existem mecanismos de proteção capazes de manter as funções fisiológicas após reembebição (Guimarães, 1999). Quanto ao tratamento de umidificação, este é apenas uma metodologia para avaliação da qualidade das sementes com umidade abaixo de $11 \%$, podendo favorecer o desempenho dessas sementes (Ellis et al. 1995). A resposta de sementes de girassol a esse tratamento foi variável, de acordo com o teste empregado. No teste de vigor que avaliou comprimento da raiz (Tabela 2), a umidificação favoreceu o desenvolvimento da plântula, principalmente em sementes mais secas, como os tratamentos Uo $(4,7 \%), \mathrm{U}_{2} \mathrm{~S}(3,2 \%)$ e $\mathrm{U}_{3} \mathrm{~S}(2,1 \%)$. Entretanto, essa diferença foi detectada somente na primeira contagem do teste de germinação, ou seja, em estágios mais precoces. $\mathrm{Na}$ última contagem, os valores médios de plântulas normais com raiz $\geq 7 \mathrm{~cm}$ foram de $79 \%$ (com umidificação) e de 84\% (sem umidificação), independente dos teores de água das sementes. Para a massa da matéria seca, independente da parte da plântula avaliada (Tabelas 4, 5 e 6), sementes não umidificadas apresentaram melhores desempenhos. Embora não tenha sido objetivo do trabalho, a contaminação das sementes previamente umidificadas pelos fungos Fusarium moniliforme e Alternaria alternata foi maior, podendo ter afetado essa característica.

Os resultados da avaliação da qualidade fisiológica das sementes desidratadas em câmara de secagem e que 
apresentaram diferenças significativas entre os teores de água e tratamento de umidificação, bem como a interação entre esses fatores encontram-se nas Tabelas 7 a 14. Sementes que foram secadas até teores de água de 2,9\% (U3C) apresentaram menor porcentagem de plântulas normais na primeira contagem do teste de germinação (Tabela 7) independente do tratamento de umidificação, ocorrendo o mesmo na última contagem do teste (Tabela 9). Ao avaliar o desenvolvimento de plântulas na primeira contagem, por meio do comprimento da raiz (Tabela 8), observa-se melhor desempenho para as sementes com teor de água de 3,2\% (U2C). Para esse teste, sementes previamente umidificadas apresentaram na média geral, melhor comportamento, como ocorrido também na secagem em sílica (Tabela 2). A diferença de comportamento deixou de existir na contagem final do mesmo teste (Tabela 10). Esses resultados confirmam a importância de se utilizar testes de vigor no acompanhamento da perda da qualidade das sementes.

TABELA 7. Valores médios de plântulas normais (\%), obtidos na primeira contagem do teste de germinação, com e sem umidificação de sementes de girassol desidratadas em câmara de secagem com diferentes teores de água.

\begin{tabular}{lcccccc}
\hline \multicolumn{1}{c}{ Tratamento } & Uo $(4,7 \%)$ & Ui $(10,2 \%)$ & U1C $(7,4 \%)$ & U2C (3,2\%) & U3C (2,9\%) & Média \\
\hline Com umidificação & $92 \mathrm{aA}$ & $89 \mathrm{aA}$ & $92 \mathrm{aA}$ & $85 \mathrm{aB}$ & $74 \mathrm{bA}$ & $86 \mathrm{~B}$ \\
Sem umidificação & $91 \mathrm{aA}$ & $92 \mathrm{aA}$ & $91 \mathrm{aA}$ & $96 \mathrm{aA}$ & $82 \mathrm{bA}$ & $90 \mathrm{~A}$ \\
\hline Média & $92 \mathrm{a}$ & $91 \mathrm{a}$ & $92 \mathrm{a}$ & $91 \mathrm{a}$ & $78 \mathrm{~b}$ & \\
\hline
\end{tabular}

Médias seguidas pela mesma letra minúscula na linha, e maiúscula na coluna, não diferem estatisticamente pelo teste Scott Knott a $5 \%$ de probabilidade. Uo: umidade original; Ui: umidade após pré-embebição para obter umidade inicial; U1C, U2C, U3C: umidades obtidas após três períodos de secagem em câmara.

TABELA 8. Valores médios de plântulas normais $(\%)$ com raiz $\geq 7 \mathrm{~cm}$, obtidos na primeira contagem do teste de germinação, com e sem umidificação de sementes de girassol desidratadas em câmara de secagem com diferentes teores de água.

\begin{tabular}{lcccccc}
\hline Tratamento & Uo $(4,7 \%)$ & Ui $(10,2 \%)$ & U1C $(7,4 \%)$ & U2C $(3,2 \%)$ & U3C $(2,9 \%)$ & Média \\
\hline Com umidificação & $53 \mathrm{aA}$ & $45 \mathrm{aA}$ & $52 \mathrm{aA}$ & $51 \mathrm{aA}$ & $30 \mathrm{bA}$ & $46 \mathrm{~A}$ \\
Sem umidificação & $26 \mathrm{bB}$ & $39 \mathrm{bA}$ & $29 \mathrm{bB}$ & $57 \mathrm{aA}$ & $38 \mathrm{bA}$ & $38 \mathrm{~B}$ \\
\hline Média & $40 \mathrm{~b}$ & $42 \mathrm{~b}$ & $41 \mathrm{~b}$ & $54 \mathrm{a}$ & $34 \mathrm{~b}$ & \\
\hline
\end{tabular}

Médias seguidas pela mesma letra minúscula na linha, e maiúscula na coluna, não diferem estatisticamente pelo teste Scott Knott a 5\% de probabilidade. Uo: umidade original; Ui: umidade após pré-embebição para obter umidade inicial; U1C, U2C, U3C: umidades obtidas após três períodos de secagem em câmara.

TABELA 9. Valores médios de plântulas normais (\%), obtidos na contagem final do teste de germinação, com e sem umidificação de sementes de girassol desidratadas em câmara de secagem com diferentes teores de água.

\begin{tabular}{lcccccc}
\hline Tratamento & Uo $(4,7 \%)$ & Ui $(10,2 \%)$ & U1C $(7,4 \%)$ & U2C $(3,2 \%)$ & U3C $(2,9 \%)$ & Média \\
\hline Com umidificação & $92 \mathrm{aA}$ & $87 \mathrm{bB}$ & $94 \mathrm{aA}$ & $91 \mathrm{aA}$ & $83 \mathrm{bA}$ & $89 \mathrm{~A}$ \\
Sem umidificação & $95 \mathrm{aA}$ & $95 \mathrm{aA}$ & $91 \mathrm{aA}$ & $96 \mathrm{aA}$ & $85 \mathrm{bA}$ & $92 \mathrm{~A}$ \\
\hline Média & $94 \mathrm{a}$ & $91 \mathrm{a}$ & $93 \mathrm{a}$ & $94 \mathrm{a}$ & $84 \mathrm{~b}$ & \\
\hline
\end{tabular}

Médias seguidas pela mesma letra minúscula na linha, e maiúscula na coluna, não diferem estatisticamente pelo teste Scott Knott a 5\% de probabilidade. Uo: umidade original; Ui: umidade após pré-embebição para obter umidade inicial; U1C, U2C, U3C: umidades obtidas após três períodos de secagem em câmara. 
TABELA 10. Valores médios de plântulas normais $(\%)$ com raiz $\geq 7 \mathrm{~cm}$, obtidos na contagem final do teste de germinação, com e sem umidificação de sementes de girassol desidratadas em câmara de secagem com diferentes teores de água.

\begin{tabular}{lcccccr}
\hline Tratamento & Uo $(4,7 \%)$ & Ui $(10,2 \%)$ & U1C $(7,4 \%)$ & U2C $(3,2 \%)$ & U3C $(2,9 \%)$ & Média \\
\hline Com umidificação & $77 \mathrm{aA}$ & $82 \mathrm{aA}$ & $82 \mathrm{aA}$ & $78 \mathrm{aA}$ & $75 \mathrm{aA}$ & $79 \mathrm{~A}$ \\
Sem umidificação & $87 \mathrm{aA}$ & $85 \mathrm{aA}$ & $71 \mathrm{bA}$ & $87 \mathrm{aA}$ & $70 \mathrm{bA}$ & $80 \mathrm{~A}$ \\
\hline Média & $82 \mathrm{a}$ & $84 \mathrm{a}$ & $77 \mathrm{~b}$ & $83 \mathrm{a}$ & $73 \mathrm{~b}$ &
\end{tabular}

Médias seguidas pela mesma letra minúscula na linha, e maiúscula na coluna, não diferem estatisticamente pelo teste Scott Knott a 5\% de probabilidade. Uo: umidade original; Ui: umidade após pré-embebição para obter umidade inicial; U1C, U2C, U3C: umidades obtidas após três períodos de secagem em câmara.

TABELA 11. Valores médios do peso da matéria seca da raiz (g), obtidos, com e sem umidificação, de sementes de girassol desidratadas em câmara de secagem com diferentes teores de água.

\begin{tabular}{lllllll}
\hline Tratamento & Uo $(4,7 \%)$ & Ui $(10,2 \%)$ & U1C $(7,4 \%)$ & U2C $(3,2 \%)$ & U3C $(2,9 \%)$ & Média \\
\hline Com umidificação & $0,0036 \mathrm{bB}$ & $0,0037 \mathrm{bA}$ & $0,0073 \mathrm{aA}$ & $0,0042 \mathrm{bA}$ & $0,0013 \mathrm{cA}$ & $0,0040 \mathrm{~A}$ \\
Sem umidificação & $0,0066 \mathrm{aA}$ & $0,0038 \mathrm{bA}$ & $0,0067 \mathrm{aA}$ & $0,0051 \mathrm{bA}$ & $0,0009 \mathrm{cA}$ & $0,0046 \mathrm{~A}$ \\
\hline Média & $0,0051 \mathrm{~b}$ & $0,0037 \mathrm{c}$ & $0,0070 \mathrm{a}$ & $0,0046 \mathrm{~b}$ & $0,0110 \mathrm{~d}$ & \\
\hline
\end{tabular}

Médias seguidas pela mesma letra minúscula na linha, e maiúscula na coluna, não diferem estatisticamente pelo teste Scott Knott a 5\% de probabilidade. Uo: umidade original; Ui: umidade após pré-embebição para obter umidade inicial; U1C, U2C, U3C: umidades obtidas após três períodos de secagem em câmara.

TABELA 12. Valores médios do peso da matéria seca da parte aérea (g), obtidos, com e sem umidificação, de sementes de girassol desidratadas em câmara de secagem com diferentes teores de água.

\begin{tabular}{lcccccc}
\hline \multicolumn{1}{c}{ Tratamento } & Uo $(4,7 \%)$ & Ui $(10,2 \%)$ & U1C $(7,4 \%)$ & U2C $(3,2 \%)$ & U3C $(2,9 \%)$ & Média \\
\hline Com umidificação & $0,0066 \mathrm{cB}$ & $0,0108 \mathrm{bA}$ & $0,0143 \mathrm{aA}$ & $0,0098 \mathrm{bA}$ & $0,0110 \mathrm{bA}$ & $0,0105 \mathrm{~B}$ \\
Sem umidificação & $0,0140 \mathrm{aA}$ & $0,0128 \mathrm{aA}$ & $0,0114 \mathrm{aA}$ & $0,0099 \mathrm{aA}$ & $0,0126 \mathrm{aA}$ & $0,0122 \mathrm{~A}$ \\
\hline Média & $0,0103 \mathrm{~b}$ & $0,0118 \mathrm{a}$ & $0,0128 \mathrm{a}$ & $0,0118 \mathrm{a}$ & $0,0118 \mathrm{a}$ & \\
\hline
\end{tabular}

Médias seguidas pela mesma letra minúscula na linha, e maiúscula na coluna, não diferem estatisticamente pelo teste Scott Knott a 5\% de probabilidade. Uo: umidade original; Ui: umidade após pré-embebição para obter umidade inicial; U1C, U2C, U3C: umidades obtidas após três períodos de secagem em câmara.

TABELA 13. Valores médios do peso da matéria seca total (g), obtidos, com e sem umidificação, de sementes de girassol desidratadas em câmara de secagem com diferentes teores de água.

\begin{tabular}{llllllc}
\hline Tratamento & Uo $(4,7 \%)$ & Ui $(10,2 \%)$ & U1C $(7,4 \%)$ & U2C $(3,2 \%)$ & U3C $(2,9 \%)$ & Média \\
\hline Com umidificação & $0,0103 \mathrm{cB}$ & $0,0145 \mathrm{bA}$ & $0,0215 \mathrm{aA}$ & $0,0140 \mathrm{bA}$ & $0,0123 \mathrm{cA}$ & $0,0145 \mathrm{~B}$ \\
Sem umidificação & $0,0206 \mathrm{aA}$ & $0,0166 \mathrm{bA}$ & $0,0181 \mathrm{aB}$ & $0,0150 \mathrm{bA}$ & $0,0135 \mathrm{bA}$ & $0,0168 \mathrm{~A}$ \\
\hline Média & $0,0154 \mathrm{~b}$ & $0,0155 \mathrm{~b}$ & $0,0198 \mathrm{a}$ & $0,0145 \mathrm{~b}$ & 0,0129 & $\mathrm{~B}$ \\
\hline
\end{tabular}

Médias seguidas pela mesma letra minúscula na linha, e maiúscula na coluna, não diferem estatisticamente pelo teste Scott Knott a 5\% de probabilidade. Uo: umidade original; Ui: umidade após pré-embebição para obter umidade inicial; U1C, U2C, U3C: umidades obtidas após três períodos de secagem em câmara. 
TABELA 14. Valores médios de condutividade elétrica $\left(\mu \mathrm{S} \mathrm{cm}^{-1} \mathrm{~g}^{-1}\right)$, obtidos, com e sem umidificação, de sementes de girassol desidratadas em câmara de secagem com diferentes teores de água.

\begin{tabular}{lcccccc}
\hline Tratamento & Uo $(4,7 \%)$ & Ui $(10,2 \%)$ & U1C $(7,4 \%)$ & U2C $(3,2 \%)$ & U3C $(2,9 \%)$ & Média \\
\hline Com umidificação & $72,88 \mathrm{aA}$ & $65,51 \mathrm{aA}$ & $69,40 \mathrm{aA}$ & $73,31 \mathrm{aA}$ & $67,04 \mathrm{aA}$ & $70,03 \mathrm{~A}$ \\
Sem umidificação & $81,79 \mathrm{bB}$ & $70,20 \mathrm{aA}$ & $75,15 \mathrm{aA}$ & $79,40 \mathrm{bA}$ & $81,04 \mathrm{bB}$ & $77,51 \mathrm{~B}$ \\
\hline Média & $77,33 \mathrm{~b}$ & $68,85 \mathrm{a}$ & $72,27 \mathrm{a}$ & $76,35 \mathrm{~b}$ & $74,04 \mathrm{~b}$ & \\
\hline
\end{tabular}

Médias seguidas pela mesma letra minúscula na linha, e maiúscula na coluna, não diferem estatisticamente pelo teste Scott Knott a 5\% de probabilidade. Uo: umidade original; Ui: umidade após pré-embebição para obter umidade inicial; U1C, U2C, U3C: umidades obtidas após três períodos de secagem em câmara.

Com relação à massa de matéria seca, independente da parte da plântula avaliada (Tabelas 11 a 13), as sementes apresentaram maior massa quando não submetidas ao tratamento de umidificação. Tem sido observado que uma das estruturas mais sensíveis aos danos de secagem é a radícula (Rosa, 2000). Pelos resultados da massa de matéria seca de raiz (Tabela 11), observam-se diferenças entre os tratamentos, com menor massa para as raízes provenientes das sementes desidratadas até $2,9 \%$ de umidade. Para a massa de matéria seca da parte aérea (Tabela 12), o tratamento de umidificação prejudicou o desempenho das sementes, sendo que as sementes controle (Uo) apresentaram menores valores. O tratamento de umidificação, por proporcionar um ambiente úmido, pode favorecer o desenvolvimento de fungos associados às sementes, e proporcionar um aumento de anormalidade de plântulas por infecção. Quando foi avaliada a massa da matéria seca total (Tabela 13), sementes desidratadas até teor de água de 7,4\% (U1C) apresentaram melhor resultado, com tendência das sementes com 2,9\% (U3C) apresentarem menor massa de matéria seca total.

Como observado para sementes desidratadas em sílica gel, o teste de condutividade elétrica (Tabela 14) apresentou menores valores quando as sementes foram previamente embebidas (umidificadas). Também foram semelhantes os valores obtidos nos dois métodos de secagem (Tabela $3 \mathrm{e}$ 14). Para as sementes que não foram umidificadas, o valor de condutividade aumentou com o progresso do processo de secagem, ou seja, do tratamento Ui $(10,2 \%)$ ao U3C $(2,9 \%)$. Isso sugere que a maior taxa de secagem observada na sílica gel influenciou a permeabilidade das membranas, ocorrendo maior quantidade de lixiviados nas primeiras horas de embebição (Rosa et al., 2000) (Tabela 3). Para a secagem em câmara (Tabela 14), as sementes com maiores teores de água (Ui e U1C), apresentaram valores mais baixos de condutividade, comprovando que sementes submetidas à secagem a conteúdos mais baixos de água podem ter seu sistema de membranas menos estruturado. Secagem conduzida até teores de água de 10,2 e 7,4\% apresentou menores valores de condutividade, concordando com os resultados obtidos nos demais testes, o que não ocorreu nas sementes secadas até teor de água de 3,2\%. Existem vários mecanismos de proteção das células contra danos de secagem capazes de manter não somente os sistemas de membranas, como também as estruturas das macromoléculas e as substâncias de reserva em condições de readquirir suas funções fisiológicas quando as sementes são reembebidas (Guimarães, 1999).

Tanto na secagem em sílica gel como em câmara foram obtidos teores de água adequados para a manutenção da qualidade das sementes, podendo ser secadas até teor de água de $3,2 \%$. Assim, para sílica gel, a secagem até teores de água de 5,3 e $3,2 \%$ proporcionou melhor desempenho das sementes em alguns testes de vigor (Tabela 2, 5 e 6), comparado ao lote original. No método de secagem em câmara, teores de água de 7,4 e $3,2 \%$ proporcionaram resultados semelhantes aos observados para sementes não desidratadas com umidade de $10,2 \%$ (Ui). No entanto, melhor desempenho das sementes, verificado pelos testes que avaliaram a massa da matéria seca e condutividade elétrica foi observado para as sementes desidratadas até $7,4 \%$ de umidade (U1C), sugerindo que a permanência por um menor tempo na câmara pode ter beneficiado essas sementes. $\mathrm{O}$ que tem sido recomendado para conservação em longo prazo é a secagem das sementes até conteúdos de água de 3-7\% (Faiad et al., 2001; Rao et al., 2007), no entanto, foi possível verificar que o efeito do teor de água das sementes após secagem sobre a qualidade fisiológica das mesmas, dependeu do método de secagem utilizado. O efeito da taxa de secagem sobre a qualidade de sementes de ipê roxo foi verificado por Gemaque et al. (2005). Os autores observaram que tanto a secagem rápida, conduzida em estufa com circulação de ar, quanto a lenta, em sala climatizada, foram eficientes em reduzir o conteúdo 
de água das sementes, mantendo a qualidade inicial do lote.

Apesar de não ter sido possível analisar estatisticamente em conjunto os dois métodos, é interessante observar os resultados obtidos para sementes com umidade de 3,2\%, comum para os dois métodos. Pode-se verificar que na secagem em sílica, houve uma superioridade dessas sementes nos testes que avaliaram o vigor de plântulas, por meio da massa da matéria seca. Provavelmente, o ambiente de secagem em sílica proporcionou algum benefício ao desenvolvimento das plântulas. A utilização de sílica gel, além de propiciar secagem a baixos conteúdos de água (ultra ssecagem) tem apresentado a vantagem de ser um ambiente asséptico, que pode ter favorecido o desempenho dessas sementes (Hong et al., 2005).

\section{CONCLUSÕES}

A desidratação em sílica gel até teor de água de 2,1\% não prejudica a germinação das sementes.

A desidratação de sementes de girassol em câmara até conteúdos de água de $2,9 \%$ proporciona redução na germinação das sementes.

Sementes de girassol podem ser desidratadas tanto em sílica gel quanto em câmara de secagem até teores de água de $3,2 \%$ de umidade, sem perda de germinação e vigor.

Tratamento de umidificação após secagem propicia melhor desenvolvimento de raiz tanto para sementes desidratadas em sílica quanto em câmara de secagem.

\section{REFERÊNCIAS}

BANZATTO, D.A.; KRONKA, S.N. Experimentação agrícola. 3.ed. Jaboticabal: FUNEP, 1995. 247p.

BRASIL. Ministério da Agricultura e Reforma Agrária. Regras para análise de sementes. Brasília, DF, 1992. 365 p.

BEWLEY, J. D.; BLACK, M. Seeds: physiology of development and germination. 2.ed. New York: Plenum, 1994. $445 \mathrm{p}$.

CARVALHO, N. M. O conceito de vigor de sementes. In: Vieira, R. D.; Carvalho, N. M. (ed). Testes de vigor em sementes. Jaboticabal: FUNEP, p.1-30, 1994.

COOLBEAR, P. Mechanisms of seed deterioration. In: Barsa, A.S. (ed). Seed quality: basic mechanisms and agricultural implications. New York: The Hawoeth Press Inc. p.223-277, 1995.

ELLIS, R. H.; HONG, T. D. Temperature sensitivity of the low-moisture content limit to negative seed longevity moisture content relationships in hermetic storage. Annals of Botany, v.97, n.5, p. 785-791, 2006.

ELLIS, R. H.; HONG, T. D.; ROBERTS, E. H. Survival and vigour of lettuce (Lactuca sativa L.) and sunflower (Helianthus annuus L.) seeds storage at low and very-low moisture contents. Annals of Botany, v. 76, n. 5, p. 521-534, 1995.

FAIAD, M. G. R.; GOEDERT, C. O.; WETZEL, M. M. V. da S.; SILVA, D. B. da; PEREIRA NETO, L. G. Banco de germoplasma de sementes da Embrapa. Brasília: Embrapa Recursos Genéticos e Biotecnologia, 2001. 31 p. (Documentos/Embrapa Recursos Genéticos e Biotecnologia, n.71).

FERREIRA,D.F. Analises estatísticas pormeio do Sisvarpara Windows versão 4. 0. In: REUNIÃO ANUAL DA REGIÃO BRASILEIRA DA SOCIEDADE INTERNACIONAL DE BIOMETRIA, 45., 2000, São Carlos. Programas e resumos... São Carlos, SP: UFSCar, 2000. p. 255-258.

GeMAQUE, R. C. R.; DAVIDE, A. C.; SILVA, E. A. A. da; FARIA, J. M. R. Efeito das secagens lenta e rápida em sementes de ipê-roxo (Tabebuia impetiginosa (Mart.) Standl.). Cerne, v. 11, n. 4, p. 329-335, 2005.

GUIMARÃES, R. M. Fisiologia de sementes: curso de especialização pós-graduação "Latu Sensu" por tutoria à distância. Lavras: UFLA-FAEPE, 1999. 132 p.

HONG, T. D.; ELLIS, R. H. A protocol to determine seed storage behavior. In: ENGELS, J. M. M; TOLL, J. Rome: IPGRI, 1996. 62p. (IPGRI Technical Bulletin n.1)

HONG, T. D.; ELLIS, R. H.; ASTLEY, D.; PINNEGAR, A. E.; GROOT, S. P. C.; KRAAK, H. L. Survival and vigour of ultra-dry seeds after ten years of hermetic storage. Seed Science and Technology, v. 33, n. 2, p. 449-460, 2005.

JOSÉ, S. C. B. R.; VON-PINHO, E. V. de R.; VON-PINHO, R. G.; RAMALHO, M. A. P.; SILVA FILHO, J. L. da. Características físicas do pericarpo de sementes de milho associadas com a tolerância à alta temperatura de secagem. Revista Brasileira de Sementes, v. 27, n.5, p. 125-131, 2005.

KRZYZANOWSKI, F. C.; VIEIRA, R. D.; NETO, J. de B. F. Vigor de sementes: conceitos e testes. ABRATES: Londrina, 1999. $218 \mathrm{p}$.

OLIVEIRA, M. F. ; VIEIRA, O. V. Extração de óleo de girassol utilizando miniprensa. Londrina: Embrapa Soja, 2004. 27p. (Documentos/Embrapa Soja, n. 237).

PÉREZ-GARCIA, F.; GONZÁLEZ-BENITO, M. E.; 
RAO, N.K.; DULLOO, M.E.; GHOSH, D.N.; LARINDE, M. Manual para el manejo de semillas en bancos de germoplasma. Manuales para Bancos de Germplasma No. 8. Bioversity International, Roma, Itália, 2007. 164p.

ROSA, S. D. V. F. da. Indução de tolerância à alta temperatura de secagem em sementes de milho por meio de pré-condicionamento a baixa temperatura. 2000. 121 f. Tese (Doutorado em Fitotecnia) - Universidade Federal de Lavras, Lavras, 2000.

STEINER, A.M.; RUCKENBAUER, P. Germination of 110 year old cereal and weed seeds, the Vienna sample of 1877. Verification of effective ultra-dry storage at ambient temperature. Seed Science Research, v. 5, n.4, p.195-199, 1995.

VALLE, R, de C. S. C. Estratégias de cultivo de células de pimenta longa (Piper hispidinervium) e determinação de parâmetros cinéticos. 2003. 165f. Tese (Doutorado em Engenharia Química) - Universidade Federal de Santa Catarina, Florianópolis, 2003.

VIEIRA, R, D,; KRZYZANOWSKI, F. C. Teste de condutividade elétrica. In: Krzyanowski, F. C.; Vieira, R. D.; França Neto, J. B. (ed.). Vigor de sementes: conceitos e testes. Londrina: ABRATES, 1999. cap.4, p.1-26. 